\title{
The Expression of PTHLH in Human Gastric Mucosa Enterochromaffin-Like Cells
}

\author{
Cuiping Liu • Jianting Chen $\cdot$ Yu Guo • \\ Lisheng Yang $\cdot$ Chengyi Zhao $\cdot$ Lan Bai
}

Received: 8 January 2010/Accepted: 29 July 2010/Published online: 16 September 2010

(C) The Author(s) 2010. This article is published with open access at Springerlink.com

\begin{abstract}
Background Gastrectomy may disturb the body's mineral homeostasis, with osteopenia and osteoporosis being among the late outcomes. Parathyroid hormone-like hormone $(P T H L H)$ was detected in rat gastric enterochromaffin-like (ECL) cells in 2005, and some researchers suggested that it was the hypothetical hormone gastrocalcin that is believed to lead to osteoporosis.

Aims Our objective was to learn whether PTHLH is expressed in human gastric ECL cells and to form a basic understanding about the relationship between PTHLH and gastrin.
\end{abstract}

\section{Liu}

GuangDong Provincial Key Laboratory of Gastroenterology Department for Gastroenterology, Nanfang Hospital, Southern Medical University, Guangzhou Road 1838, 510515 Guangzhou, Guangdong Province, China

e-mail: bullebell@163.com

J. Chen - C. Zhao

Department of Orthopaedics and Traumatology, Nanfang

Hospital, Southern Medical University, Guangzhou Road 1838,

510515 Guangzhou, Guangdong Province, China

e-mail: chenjt@fimmu.com

C. Zhao

e-mail: zhaocy@sina.com

\section{Y. Guo $\cdot$ L. Yang $\cdot$ L. Bai $(\square)$}

Department of Huiqiao Building, Nanfang Hospital, Southern Medical University, Guangzhou Road 1838, 510515 Guangzhou, Guangdong Province, China

e-mail: blan9988@163.com

Y. Guo

e-mail: guoyuzhengwu@yaho.com.cn

L. Yang

e-mail: yangls@ fimmu.com
Methods We collected normal human gastric mucosa specimens and serum samples from 28 patients.

Results RT-PCR and immunohistochemical analysis demonstrated weak expression of PTHLH in ECL cells at the RNA and protein levels. A low level of PTHLH expression was also found in the serum. Serum gastrin did have a significant positive correlation with the relative ratio of PTHLH mRNA to $\beta$-actin levels in gastric mucosa $\left(r_{s}=0.569, p=0.002\right)$.

Conclusions This indicates that PTHLH has a low signal expression in human gastric ECL cells and that serum gastrin levels correlate with PTHLH RNA levels in gastric mucosa. Further work is needed to evaluate the functional role of PTHLH in ECL cells and to determine whether PTHLH is gastrocalcin.

Keywords PTHLH - Osteoporosis · ECL cells · Gastrocalcin

\section{Background}

The phenomenon of gastrectomy-evoked osteopathy has been known for over 50 years [1]. Although many studies have confirmed that surgical removal of the whole stomach (gastrectomy) or of the acid-producing part of the stomach (fundectomy) results in significant bone loss, the mechanism remains poorly understood. Neither dietary deficiency (calcium, vitamin D) nor lack of gastric acid is the main reason for bone loss [2-6]. One hypothesis is that a hypothetical hormone (dubbed "gastrocalcin") causes bone loss and is produced by ECL cells (enterochromaffin-like cells, the predominant endocrine cell population in the oxyntic mucosa) [7]. Gastrocalcin is known not to be histamine or pancreastatin, but like them, it can be stimulated 
by gastrin. Gastrin, therefore, has an indirect effect on bone by causing the release of gastrocalcin. Mediated by an IP3signaling pathway, gastrocalcin can increase $\left[\mathrm{Ca}^{2+}\right]$ in osteoclast-like cells $[8,9]$. At present, we do not know the RNA or protein structure for gastrocalcin.

Parathyroid hormone-like hormone (PTHLH) was initially discovered when it was found to be the cause of a common lethal paraneoplastic syndrome, humoral hypercalcemia of malignancy [10]. It is now well established that PTHLH can be expressed in many normal tissues and cell types, such as the cardiovascular system, endothelial cells, and smooth muscle cells, and plays important roles during both development and adulthood. As the PTHLH mRNA is unstable, and the protein itself is susceptible to extensive proteolytic processing, it is considered to be a paracrine or autocrine factor [11-13]. A global gene expression fingerprint of mouse stomach ECL cells was described in 2005, and researchers have found the PTHLH gene in ECL cells and noted that expression of this gene can be altered by gastrin [14]. To our knowledge, the expression and roles of PTHLH in normal human gastric mucosa are still unknown.

Researchers have presumed that PTHLH secreted by ECL cells is the hypothetical hormone gastrocalcin, and that it contributes to the regulation of calcium deposition in bone and to the maintenance of normal bone mass. The aim of our study was to obtain a basic understanding of the expression and location of PTHLH in human normal gastric mucosa and to identify factors that may influence PTHLH production.

\section{Materials and Methods}

\section{Specimens}

Specimens of normal gastric mucosa were collected from twenty-eight patients, mainly from the fundus. The group was composed of nineteen men and nine women, with ages ranging from 33 to 75 years. Routine blood and biochemistry tests were performed initially, and subjects with a normal nutritional status or only slight malnutrition were allowed to remain in the study. A serum sample was collected from each individual and stored at $-80^{\circ} \mathrm{C}$ until used. Part of each specimen was stored at $-80^{\circ} \mathrm{C}$ for later extraction of total RNA and the rest was fixed in $10 \%$ buffered formalin and embedded in paraffin. These sections were stained with hematoxylin and eosin (H\&E) and used for immunohistochemistry. All the specimens were obtained from the Departments of General Surgery, Chest Surgery, and Gastroenterology, Nanfang Hospital, Southern Medical University, Guangzhou. All subjects gave their informed oral and written consent for their samples to be used in this project.
Reverse Transcription PCR

Total RNA was extracted from each gastric mucosa sample using Trizol (Tiangen Corporation, China), and the RNA quality and concentration were assessed using a spectrophotometer system (Unicam, America). Samples with an A260/A280 ratio $\geq 1.8$ were used for polymerase chain reaction (PCR). An amount of 2 ug of each RNA sample was used to prepare cDNA. The semi-quantitative PCR primer sequences for PTHLH and PTHR were: PTHLH (287 bp): 5'-AGC CCT CTC CCA ACA CAA AG-3'(forward); 5'-AAG TGC TGT ACG TGA ATC GAG-3'(reverse); PTHR1 (376 bp): 5'-CTT CAA GCG AAA GGC ACG-3'(forward); 5'-CCA TCC ACT ATG TCA GCA GGT-3'(reverse); PTHR2 (312 bp): 5'-CAG CAT GGG CTG TGG CAC GA$3^{\prime}$ (forward); 5'-GCA TGC GGA TCT CCC ACC CG-3' (reverse); $\beta$-actin (194 bp): $5^{\prime}$-CCA TCG TCC ACC GCA AAT-3'(forward); $5^{\prime}$-GCT GTC ACC TTC ACC GTT C-3' (reverse). Total RNA obtained from breast carcinoma tissue was used as the positive control for PTHLH and PTHR. A negative control in which the cDNA was replaced by water was used to detect any contamination.

Next, quantitative reverse transcriptase polymerase chain reactions (qRT-PCR) for PTHLH were performed using the SYBR GreenER qPCR SuperMix Universal (Invitrogen) and an Applied Biosystems system (ABI 7500, USA). The sequences of the PTHLH and $\beta$-actin forward and reverse primers were: $5^{\prime}$-GGC GAC GAT TCT TCC TTC AC-3', 5'-GTT GGG AGA GGG CTT GGA GT- $3^{\prime}$; $5^{\prime}$-GCA TGG GTC AGA AGG ATT CCT-3', $5^{\prime}$-TCG TCC CAG TTG GTG ACG AT- $3^{\prime}$. All reactions were run in triplicate, and the mean value was used to calculate the ratio of PTHLH / $\beta$-actin expression in each sample.

\section{Immunohistochemistry}

Routine serial sections of formaldehyde-fixed, paraffinembedded tissue blocks of the oxyntic mucosa were cut into $4-\mu m$-thick slices, then deparaffinized with xylene and rehydrated through a series of ethanol solutions. After pressure cooking for $20 \mathrm{~min}$ in EDTA buffer $(\mathrm{pH} \mathrm{8.0)}$ and washing with PBS, the sections were incubated in $3 \%$ hydrogen peroxide for $15 \mathrm{~min}$ to block endogenous peroxidase activity, immersed in PBS, and then incubated in PBS containing $10 \%$ normal goat serum for $1 \mathrm{~h}$ at room temperature to prevent nonspecific binding, and then incubated overnight at $4{ }^{\circ} \mathrm{C}$ with primary antibody for PTHLH (mouse monoclonal IgG antibody, Abnova, America), HDC (rabbit polyclonal IgG antibody, Boster, China) and $\mathrm{CgA}$ (rabbit polyclonal IgG antibody, a kind gift from Professor Shen Hong) with optimal dilutions of 1:400, 1:100, and 1:200, respectively. $\mathrm{HDC}$ and $\mathrm{CgA}$ were used as the markers for ECL cells. The primary antisera were diluted in 
phosphate-buffered saline (PBS) containing $0.02 \%$ Trion $\mathrm{X}-100$ (PBS-T) and 5\% bovine serum albumin (BSA).

Sections were washed in PBS for $15 \mathrm{~min}$, and bound antibodies were localized by the avidin-biotin-peroxidase method using diaminobenzidine as the chromogenic substrate. The slides were counterstained with hematoxylin and mounted for examination. Another section was stained with $H \& E$. Negative controls were prepared in each case by replacing the primary antibody with PBS. A Zeiss Axiovert $100 \mathrm{M}$ confocal microscope (Carl Zeiss Inc. Thornwood, NY, USA) was used to visualize fluorescence and to collect the images.

\section{Serum PTHLH and Gastrin Levels Measured by ELISA} and RIA

Quantitative measurements of serum PTHLH were performed with enzyme-linked immunosorbent assays (ELISA) using kits obtained from the R\&D system. The levels of PTHLH were expressed as pmoles per liter of serum. Absorbance measurements were performed at $450 \mathrm{~nm}$ using a spectrophotometer system (US). Gastrin immunoreactivity was measured using a commercially available radioimmunoassay (RIA) kit (Atomic Energy Research Institute, Beijing, China). The amount of gastrin released was analyzed with an SN-695 gamma counter RIA program and expressed as pmoles per well.

\section{Data Analysis}

All results were confirmed in multiple independent experiments, with each time point or condition assayed in triplicate within each experiment. Data are expressed as means \pm SD. The correlation between those indexes was determined using bivariate analysis. $p<0.05$ was regarded as significant.

\section{Results}

\section{Clinical Data}

Seven samples were obtained via endoscopy from patients with a diagnosis of chronic superficial gastritis (CSG) or no abnormalities; the other twenty-one samples came from surgical cases, and the diagnoses were one esophageal carcinoma, five carcinomas of the gastric fundus, eight carcinomas of the gastric body, six carcinomas of the sinus ventriculi and one case of superficial gastritis located in the sinus ventriculi. We selected our samples from at least $5 \mathrm{~cm}$ away from the lesion site. Blood calcium concentrations ranged from 1.8 to $2.39 \mathrm{mmol} / \mathrm{l}$, with a mean value of $2.1686 \pm 0.1385$; there were no cases of hypercalcemia.
The serum albumin ranged from 30.8 to $48.8 \mathrm{~g} / \mathrm{l}$; some patients had slight asymptomatic hypoproteinemia.

\section{PTHLH and PTHR1 Expression in Human Gastric} Mucosa

PCR detected 284 and 358 bp products. These products corresponded to the expected sizes of the PTHLH and PTHR1 amplicons which would have been produced with our primers (Fig. 1a). However, PTHR2 mRNA was not detected. The tissue distribution of PTHLH mRNA was quantitatively evaluated using RT-PCR (qPCR), and the results normalized by $\beta$-actin. The relative ratio of PTHLH mRNA to $\beta$-actin ranged from 0.0205 to 1.5926 , with a mean value of $0.4359 \pm 0.4108$.

Distribution of ECL Cells in the Gastric Mucosa by Immunohistochemistry

When the expression of $\mathrm{HDC}$ and $\mathrm{CgA}$ was investigated using immunohistochemical staining of serial sections, positive cells of the two indexes were almost in the same batch. The positive cells had erythroic cytoplasms on HE staining, and it was difficult to distinguish them from acidproducing cells. These positively strained cells, which we concluded were ECL cells, were mainly located in the lower half of the oxyntic mucosa, with $0-5$ cells per glandular tube.

\section{Expression of PTHLH in ECL Cells}

Immunoreactivity for PTHLH was detected in the normal gastric mucosa, mainly in the basal part of the oxyntic gland, and no such staining was seen on the surface of the tissue or in the glandular epithelium. The immunoreactive intensity was faint. PTHLH was mainly in the cytoplasm, but could also be seen in the nucleus (Figs. 2, 3). Immunohistochemical analysis of serial sections confirmed the presence of PTHLH in ECL cells (Figs. 2, 3).

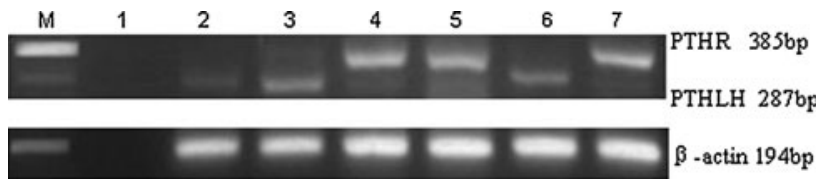

Fig. 1 RT-PCR for PTHLH and PTHR1 in the normal gastric mucosa samples. a The RT-PCR analysis revealed expression of PTHLH and PTHR1 in the normal gastric mucosa. Lane 1 negative controls. Lane 2 samples from endoscopy for PTHLH. Lane 3 samples from surgery for PTHLH. Lane 4 samples from enterology for PTHR1. Lane 5 samples from surgery for PTHR1. Lane 6 and 7 positive controls for PTHLH and PTHR1, respectively. The results were normalized to $\beta$-actin. b An example of the results of PTHLH detected by qRT-PCR. $\beta$-actin was used as a control 
Fig. 2 Distribution of ECL cells (a CgA and b HDC) and PTHLH (c) in the gastric fundic mucosa by immunohistochemical analysis of serial sections. H\&E staining (d) was also detected within the sections (magnification: $\times 200$ )
Fig. 3 The expression of PTHLH (b) in ECL cells in serial sections by immunohistochemical analysis. HDC (a) represents ECL cells. Positive cells were mainly located in the basal part of the oxyntic mucosa (magnification: $\times 400$ )

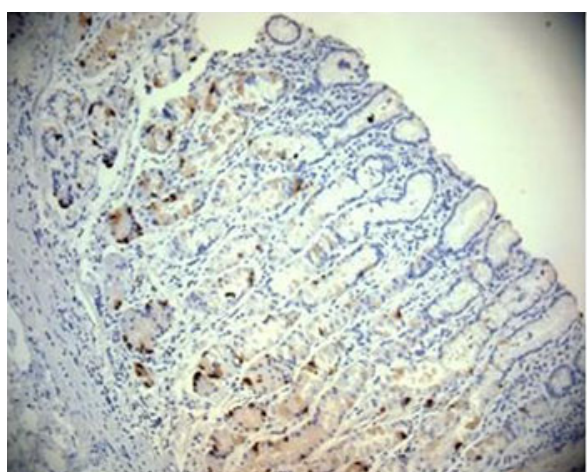

a

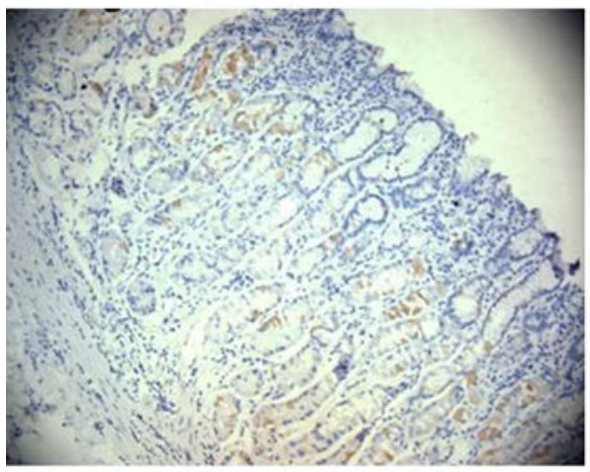

C

PTHLH

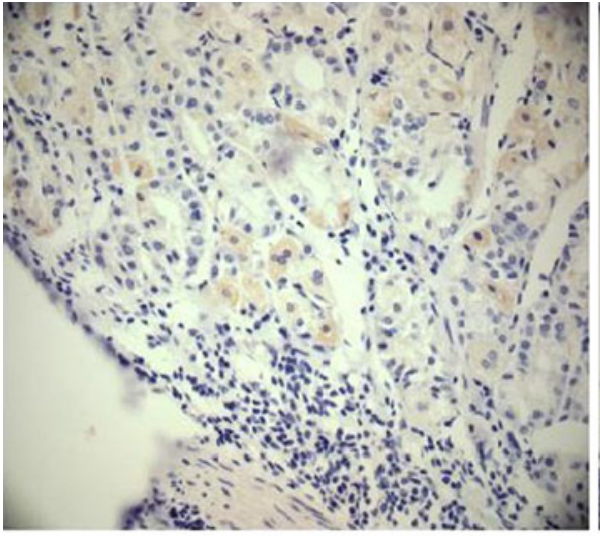

a

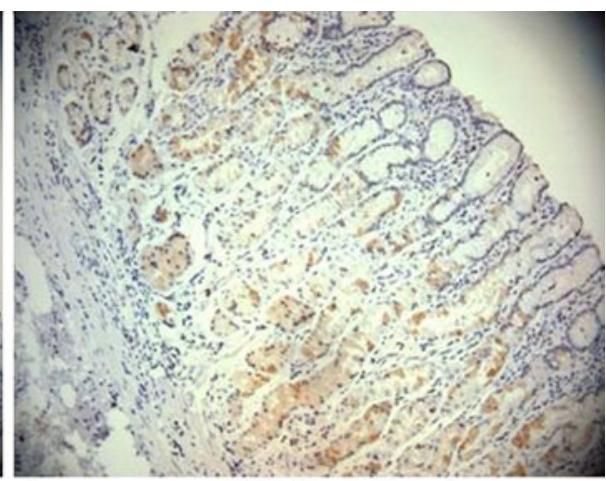

b

HDC

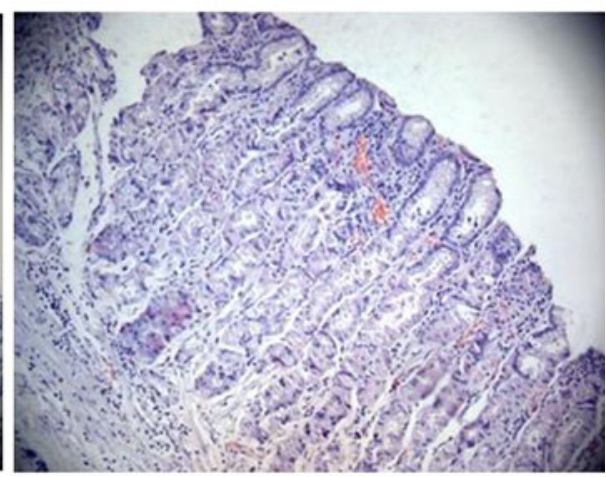

d

$\mathrm{HE}$

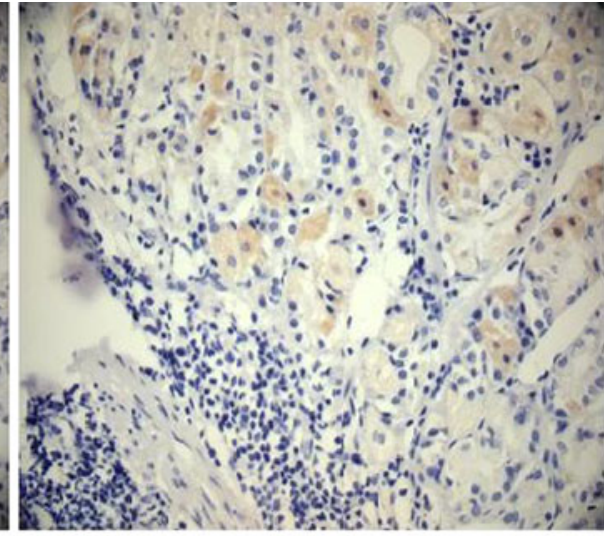

b
PTHLH
Serum PTHLH and Gastrin Levels and Their Correlations

The expression of serum PTHLH in each case was low, the mean value in the 28 cases was $2.2195 \pm 2.0364 \mathrm{pmol} / 1$ with a range of 0.39 to $9.36 \mathrm{pmol} / 1$. The mean value of serum gastrin level was $90.2650 \pm 46.3116 \mathrm{pg} / \mathrm{ml}$ and a range of 232.32 to $22.38 \mathrm{pg} / \mathrm{ml}$. The serum gastrin level had a significant positive correlation with the relative ratio of PTHLH mRNA level to $\beta$-actin (correlation coefficient $r_{s}=0.569, p=0.002$ ), but serum gastrin had no correlation with serum PTHLH $\left(r_{s}=0.085, p=0.668\right)$. Table 1 shows the correlation.

\section{Discussion}

PTHLH was initially discovered when it was found to be the cause of the common lethal paraneoplastic syndrome humoral hypercalcemia of malignancy (HHM). It shares a significant $N$-terminal amino acid sequence homology with

Table 1 The correlation between PTHLH and gastrin

\begin{tabular}{lll}
\hline Correlation & $\mathrm{R}$ (correlation) & $p$ \\
\hline hPTHrP (mRNA) vs. gastrin & $0.569^{* *}$ & 0.002 \\
hPTHrP (serum) vs. gastrin & 0.085 & 0.668 \\
\hline
\end{tabular}

** $P<0.05$ 
PTH, and the two hormones have a similar structure that allows them to bind and activate their common receptor, PTHR1. Both hormones can bind to PTHR1 through PKA and PKC signal conduction [15-17]. The parathyroid hormone receptor (PTHR) is a class B G protein-coupled receptor that plays critical roles in bone and mineral ion metabolism. There may be several receptors: PTHR1 is the most common one, but a second PTH receptor (PTHR2) has been described $[15,16]$ and others have been postulated [17]. However, the expression of PTHR2 appears to be limited to the pancreas, brain, kidney, and testes, and this isoform does not bind PTHLH. In our study, PTHLH was detected in adult human gastric mucosa using RT-PCR and immunohistochemistry, albeit with a faint signal. This suggests that PTHLH is expressed in normal tissue at levels far lower than those observed in cancers associated with HHM. We designed two primers for PTHR1 and PTHR2, respectively, but only PTHR1 was detected; this agrees with previous studies showing that only PTHR1 is the common receptor for PTH and PTHLH. However, the signaling pathways of PTHLH and PTHR1 and their roles in gastric mucosa need further study.

The gastric mucosa is rich in endocrine cells. It contains $\mathrm{G}$ cells that secret gastrin, D cells (somatostatin), enterochromaffin cells that secret serotonin (5-HT), and ECL cells (enterochromaffin-like cells). G cells are located mainly in the gastric pyloric gland, and gastrin stimulates parietal cells to secret hydrochloric acid [18-20]. ECL cells are the most frequent cells in the oxyntic mucosa (the fundic glands) and are mainly buried in the chief cells and parietal cells located in the basal or caudomedial part of the gland. They play a pivotal role in controlling gastric acid secretion by virtue of their ability to secrete histamine in response to gastrin. Histidine decarboxylase (HDC) in the cytosol catalyses the formation of histamine. Chromogranin A-derived peptides ( $\mathrm{CgA})$, such as pancreastatin, are secreted in parallel with histamine secretion following stimulation by gastrin [21, 22]. Among epithelial cells in the oxyntic mucosa, only ECL cells express HDC, and HDC is specific for that cell type [23, 24]. We used HDC and $\mathrm{CgA}$ to detect ECL cells and examined serial mucosal sections to determine whether PTHLH was expressed in the gastric mucosa. As the slices were only $4 \mu \mathrm{m}$ apart, we think that the molecular organization in the serial sections was expressed by the same position. Our study showed that HDC and CgA had a similar level of expression in the gastric fundic mucosa, that the presence of both HDC and $\mathrm{CgA}$ indicated the presence of ECL cells, and that PTHLH was expressed by the HDC/CgA-positive cells, or, in other words, that PTHLH could be expressed by ECL cells.

Serum PTHLH expression was also faint, even in the patient who had a malignant tumor without $\mathrm{MHH}$; the highest level was only $9.3556 \mathrm{pmol} / \mathrm{l}$, in a patient with
CSG. Perhaps high levels of expression occur only in HMM. We found that serum gastrin levels had a significant positive correlation with gastric PTHLH mRNA levels $\left(r_{s}=0.569, p<0.01\right)$. This may be in agreement with previous studies showing that PTHLH secretion in rat ECL cells is controlled by gastrin $[8,9,21]$. Our two cases with the highest expression of PTHLH mRNA (1.5926 and $1.5691 \mathrm{pmol} / \mathrm{l})$ had high serum gastrin levels (132.00 and $232.32 \mathrm{pg} / \mathrm{ml}$ ). This further supports our view that the high expression of PTHLH mRNA was due to the high serum gastrin levels. However, with the case that had the lowest PTHLH mRNA expression (0.0205 pmol/l), the serum gastrin was $101.92 \mathrm{pg} / \mathrm{ml}$. Perhaps other factors, such as malignancy, influence PTHLH expression in the gastric mucosa. As we tested only 28 cases, despite our finding of a positive correlation between serum gastrin and gastric PTHLH mRNA levels, further studies are required to prove the relationship between gastrin and PTHLH in ECL cells.

In our study, serum gastrin had no significant correlation with plasma PTHLH. However, as PTHLH can be expressed by a variety of healthy tissues, perhaps the serum PTHLH levels reflected the total amount secreted by a number of different tissues and not just the stomach. Furthermore, some researchers have proposed that PTHLH is a ubiquitously produced local paracrine and autocrine factor and does not normally appear in the circulation. Therefore, we suggest that serum PTHLH does not perfectly reflect secretion from the gastric mucosa, and that testing serum PTHLH in order to determine the ratio with gastrin levels in the gastric mucosa does not produce useful data. PTHLH selectively stimulates bone formation and has a rapid onset of action, and experimental and clinical research shows that even large doses are safe [13, 25-28].

Consequently, its use is accepted in clinical practice. If PTHLH is gastrocalcin, then we have an effective way to treat gastrectomy-evoked osteopathy. In conclusion, our research proved that human gastric ECL cells can secrete PTHLH and that gastric levels of PTHLH have a positive correlation with gastrin secretion, suggesting that PTHLH may be a candidate peptide hormone for gastrocalcin. Further studies are needed to evaluate its functional role and signaling pathway in ECL cells, if it is indeed gastrocalcin, and to explore an indirect but simple way to obtain information about its expression in gastric mucosa.

Acknowledgments This work was supported by grants from the Science and Technology Foundation of Guangdong, China, and industry proceedings of Guangdong, China (No. 2007B03070002 and 2008B011000003) and the Science and Technology Foundation of Baiyun District (2009-SZ-35). We also wish to acknowledge the following institutions for their support of this work: the Department of General Surgery, the Department of Chest Surgery, and the Clinical Research Center of Nanfang Hospital affiliated with Southern Medical University. Thanks also to Professor ShenHong, Doctor Chen Chudi, and Wang Yadong. 
Competing interests We have some non-financial competing interests to publish this paper, such as academic and personal reasons. We hope that our results were recognized.

Open Access This article is distributed under the terms of the Creative Commons Attribution Noncommercial License which permits any noncommercial use, distribution, and reproduction in any medium, provided the original author(s) and source are credited.

\section{References}

1. Andersson N, Surve W, Lehto-Axtelius D, et al. Drug-induced prevention of gastrectomy-and ovariectomy-induced osteopaenia in the young female rat. $J$ Endocrinol. 2002;175(3):695-703.

2. Persson P, Gaqnemo-Persson R, Chen D, et al. Gastrectomy causes bone loss in the rat: is lack of gastric acid responsible? Scand J Gastroenterol. 1993;28(4):301-306.

3. Adachi Y, Shiota E, Matsumata T, et al. Bone mineral density in patients taking H2-receptor antagonist. Calcif Tissue Int. 1998; 62(4):283-285.

4. Klinge B, Lehto-Axtelius D, Akerman M, et al. Structure of calvaria after gastrectomy. An experimental study in the rat. $J$ Clin Endocrinol. 1995;30(10):952-957.

5. Schmiedl A, Schwille PO, Stuhler C, et al. Low bone mineral density after total gastrectomy in males: a preliminary report emphasizing the possible significance of urinary net acid excretion, serum gastrin and phosphorus. Clin Chem Lab Med. 1999; 37(7):739-744.

6. Davies M, Heys SE, Selby PL, et al. Increased catabolism of 25hydroxyvitamin D in patients with partial gastrectomy, elevated 1, 25-dihydroxyvitamin D levels. Implications for metabolic bone disease. J Clin Endocrinol Metab. 1997;82(1):209-212.

7. Persson P, Häkanson R, Axelson J, et al. Gastrin releases a blood calcium-lowering peptide from the acid-producing part of the rat stomach. Proc Natl Acad Sci USA. 1989;86(8):2834-2838.

8. Larsson B, Gritli-Linde A, Norlen P, et al. Extracts of ECL-cell granules/vesicles, of isolated ECL cells from rat oxyntic mucosa evoke a $\mathrm{Ca}$ second messenger response in osteoblastic cells. Regul Pept. 2001;97(2-3):153-161.

9. Larsson B, Norlen P, Lindstrom E, et al. Effects of ECL cell extracts and granule/vesicle-enriched fractions from rat oxyntic mucosa on cAMP and IP3 in rat osteoblast-like cells. Regul Pept. 2002;106(1-3):13-18. Jun 15

10. Burtis WJ, Wu T, Bunch C, et al. Identification of a novel 17,000Dalton parathyroid hormone-like adenylate cyclase-stimulating protein from a tumor associated with humoral hypercalcemia of malignancy. J Biol Chem. 1987;262(15):7151-7156.

11. Meyer R, Schreckenberg R, Kretschmer F, et al. Parathyroid hormone-related protein (PTHrP) signal cascade modulates myocardial dysfunction in the pressure overloaded heart. Eur $J$ Heart Fail. 2007;9(12):1156-1162.

12. Sharpe GR, Dillon JP, Durham B, et al. Human keratinocytes express transcripts for three isoforms of parathyroid hormonerelated protein $(\mathrm{PTHrP})$, but not for the parathyroid hormone/
PTHrP receptor: effects of $1,25(\mathrm{OH}) 2$ vitamin D3. British $J$ Dermatology. 1998;138(6):944-951.

13. Martin TJ. Osteoblast-derived PTHrP is a physiological regulator of bone formation. J Clin Invest. 2005;115(9):2322-2324.

14. Andersson N, Skrtic SM, Hakanson R, et al. A gene expression fingerprint of mouse stomach ECL cells. Biochem Biophys Res Commun. 2005;332(2):404-410.

15. Reppe S, Stilgren L, Abrahamsen B, et al. Abnormal muscle and hematopoietic gene expression may be important for clinical morbidity in primary hyperparathyroidism. Am J Physiol Endocrinol Metab. 2007;292(5):E1465-E1473.

16. Tenne M, McGuigan F, Jansson L. Genetic variation in the PTH pathway, bone phenotypes in elderly women: evaluation of PTH, PTHLH, PTHR1, PTHR2 genes. Bone. 2008;42(4):719-727.

17. Orloff JJ, Stewart AF. The carboxy-terminus of parathyroid hormone-inert or invaluable? Endocrinology. 1995;136:47294731 .

18. Torbergsen $\mathrm{K}$, Wiksen $\mathrm{H}$, Johansen $\mathrm{K}$, et al. Immunoreactivity of gastric ECL, A-like cells infasted, fed rats, mice. Biotechnic Histochem. 2005;80(1):21-30.

19. Bjorkqvist M, Dornonville de la Cour C, Zhao CM, et al. Role of gastrin in the development of gastric mucosa, ECL cells, A-like cells in newborn, young rats. Reg Pept. 2002;108(2-3):73-82.

20. Kidd M, Modlin IM, Black JW, et al. A comparison of the effects of gastrin, somatostatin and dopamine receptor ligands on rat gastric enterochromaffin-like cell secretion and proliferation. Regulatory Peptides. 2007;143(1-3):109-117.

21. Nishi T, Makuuchi H, Weinstein M, et al. Changes in gastric ECL cells, parietal cells after long-term administration of high-dose omeprazole to patients with Barrett's esophagus. Tokai J Exp Clin Med. 2005;30(2):117-121.

22. Lindstrom E, Chen D, Norlen P, et al. Control of gastric acid secretion: the gastrin-ECL cell-parietal cell axis. Comp Biochem Physiol A Mol Integr Physiol. 2001;128(3):505-514.

23. Bjorkgvist M, Bernsand M, Eliasson L, et al. Somatostatin, misoprostol and galanin inhibit gastrin-and PACAP-stimulated secretion of histamine and pancreastatin from ECL cells by blocking specific $\mathrm{Ca}^{2+}$ channels. Regulatory Peptides. 2005; 130(1-2):81-90.

24. Rubin W, Schwartz B. Electron microscopic radioautographic identification of the ECL cell as the histamine-synthesizing endocrine cell in the rat stomach. Gastroenterology. 1979;77(3): 458-467.

25. Rosen CJ, Bilezikian JP. Clinical review 123: anabolic therapy for osteoporosis. J Clin Endocrinol Metab. 2001;86(3):957-964.

26. Horwitz MJ, Tedesco MB, Gundberg C, et al. Short-term, highdose parathyroid hormone-related protein as a skeletal anabolic agent for the treatment of postmenopausal osteoporosis. J Clin Endocrinol Metab. 2003;88(2):569-575.

27. Plotkin H, Gundberg C, Mitnick M, et al. Dissociation of bone formation from resorption during two-week treatment with human parathyroid hormone-related peptide-(1-36) in humans: potential as an anabolic therapy for osteoporosis. J Clin Endocrinol Metab. 1998;83(8):2786-2791.

28. Bisello A, Horwitz MJ, Stewart AF. Parathyroid hormone-related protein: an essential physiological regulator of adult bone mass. Endocrinology. 2004;145(8):3551-3553. 